\title{
CARÁTER STAY-GREEN E PRODUTIVIDADE DE GRÃOS EM TRIGO ( ${ }^{1}$ )
}

\author{
JOSÉ ANTONIO GONZALEZ DA SILVA $\left({ }^{2}\right)$; FERNANDO IRAJÁ FÉLIX DE CARVALHO $\left({ }^{3 *}\right)$; \\ IRINEU HARTWIG $\left({ }^{3,4}\right)$; ANTONIO COSTA DE OLIVEIRA $\left({ }^{3}\right)$; IVANDRO BERTAN $\left({ }^{3,4}\right)$; \\ VANDERLEI DA ROSA CAETANO $\left({ }^{5}\right)$; DOUGLAS ANDRÉ MALLMANN SCHMIDT $\left({ }^{3,6}\right)$; \\ IGOR PIRES VALÉRIO $\left({ }^{3,6}\right)$; GUILHERME RIBEIRO $\left({ }^{3,6}\right)$; CYRANO CARDOSO BUSATO $\left({ }^{3}\right)$
}

\begin{abstract}
RESUMO
O caráter stay-green é um dos fatores que poderá auxiliar o melhorista na obtenção de plantas mais produtivas, devido à permanência verde por um período mais prolongado favorecendo o enchimento de grãos. Desta forma, o objetivo do trabalho foi o de avaliar o desempenho de diferentes constituições genéticas de trigo com e sem a presença do caráter stay-green e verificar se a expressão de alelos que intensificam a coloração verde por um período mais prolongado, os quais auxiliam no incremento da produtividade de grãos. O trabalho foi desenvolvido em campo experimental com delineamento de blocos casualizados com três repetições, em dois anos de cultivo. A presença de constituições genéticas superiores facilita os benefícios expressos pelo caráter stay-green na produtividade de grãos. O caráter stay-green proporciona estabilidade na produtividade de grãos sob efeito de diferentes ambientes.
\end{abstract}

Palavras-chave: Triticum aestivum L., permanência verde, melhoramento de plantas.

\section{ABSTRACT \\ STAY-GREEN TRAIT AND WHEAT GRAIN YIELD}

The stay-green trait is one of the factors that can aid the breeder in obtaining higher yielding plants due to a delay in leaf senescence, favouring grain filling. The objective of this study was to evaluate the performance of different wheat lines with and without the stay-green trait and investigate if longer green period; foster an increment of grain yield. The field experiment was conducted in randomized complete block design with three replications in two crop years. Genetically superior lines facilitate the benefits of the stay-green trait for grain yield. The stay-green trait promotes yield stability under different environments.

Key words: Triticum aestivum L., green permanence, plant breeding.

(1) Recebido para publicação em 5 de dezembro de 2006 e aceito em 5 de julho de 2007.

$\left({ }^{2}\right)$ Departamento de Estudos Agrários - Agronomia/Universidade Regional do Noroeste do Estado do Rio Grande do Sul (Unijui), 98700-000 Ijui (RS). E-mail: jose.gonzales@unijui.edu.br

$\left({ }^{3}\right)$ Centro de Genômica e Fitomelhoramento, Faculdade de Agronomia “Eliseu Maciel” (FAEM)/Universidade Federal de Pelotas (UFPel), Caixa Postal 354, 96010-900 Pelotas (RS). E-mail: carvalho@ufpel.tche.br* (autor correspondente); iriwig@ufpel.tche.br; acostol@terra.com.br; ivandrobertan@yahoo.com.br; damschmidt2003@yahoo.com.br; igorvalerio@gmail.com; guilherme.tche@gmail.com; cyrano_agronomo@yahoo.com.br

$\left({ }^{4}\right)$ Bolsista Pós Doutorado Júnior (CNPq).

$\left({ }^{5}\right)$ Embrapa Clima Temperado, Caixa Postal 403, 96001-970, Pelotas (RS). E-mail: vcaetano@cpact.embrapa.br

$\left({ }^{6}\right)$ Bolsista Pós-Graduação (Capes). 


\section{INTRODUÇÃO}

O comportamento da manifestação fenotípica em genótipos stay-green revela um prolongamento na duração da área verde dos colmos e das folhas, determinando que a fase de senescência se estenda e inicie de cima para baixo na planta; os colmos e as folhas são as últimas estruturas a secar, possibilitando que os fotoassimilados dessas estruturas estejam disponíveis para translocação durante toda a fase de enchimento dos grãos. Diferentemente do trigo sem a presença do caráter (maturação sincronizada), em que a senescência ocorre de baixo para cima e a espiga é a última estrutura a maturar, o que pode impedir a perfeita formação dos grãos se o aporte e translocação de fotoassimilados forem insuficientes (GoNG et al., 2005).

A incorporação do caráter stay-green em novas constituições genéticas de trigos brasileiros pode representar uma excelente ferramenta na obtenção de genótipos superiores, visto que, este caráter tem sido relatado por haverar uma associação positiva com aumento na produtividade de grãos e expressiva tolerância ao frio e ao calor (WALULU et al., 1994; Cukadar-Olmedo and Miller, 1997; Silva et al., 2003). Além disso, têm demonstrado ser promissor em atribuir qualidade ao trigo (WALULU et al., 1994), maior capacidade de acumular matéria seca, devido ao aumento na produção de fotoassimilados (GENTINETTA et al., 1986; SILVA et al., 2003) e maior resistência ao acamamento (CuKadAR-Olmedo e Miller, 1997). Desta forma, o trigo é positivamente responsivo à maior aplicação de nitrogênio, favorecendo o maior enchimento dos grãos.

Estudando a herança do caráter stay-green em sorgo, observaram-se ação de dominância parcial da maior área verde sobre a menor área (OOSTEROM et al., 1996). Em trigo, foi constatado ser caráter de alta herdabilidade, controlado por um único gene com dois alelos, com ação gênica de dominância parcial e grande participação da aditividade (SILVA, 1999). A ação de genes menores, ou seja, de pequeno efeito, não tem sido expresso em publicações científicas até o momento. Por esse motivo, evidencia ser caráter de fácil seleção em gerações altamente segregantes e, portanto, com grande possibilidade de ganho genético, pois, mediante o teste de progênie em $\mathrm{F}_{3}$, possibilita separar fenotipicamente o heterozigoto do homozigoto dominante.

O caráter stay-green também está correlacionado com escores protéicos obtidos através da análise eletroforética das subunidades de gluteninas de alta massa molecular, podendo ser sugerido como parâmetro na seleção de plantas superiores em gluteninas, e conseqüentemente, com maior qualidade de panificação (SILva et al., 2004). Desta forma, o emprego do caráter stay-green poderá contribuir sobremaneira no aumento de enchimento de grãos pela permanência verde da planta de trigo por período maior, determinando incremento na produtividade de grãos, associado ao aumento na qualidade industrial de panificação, o que representa forte estratégia para tornar o trigo brasileiro mais competitivo no mercado nacional.

O objetivo do trabalho foi o de avaliar o desempenho de diferentes constituições genéticas de trigo com e sem a presença do caráter stay-green e verificar se a expressão de alelos que intensifica a coloração verde por período mais prolongado, auxilia no incremento da produtividade de grãos.

\section{MATERIAL E MÉTODOS}

O experimento foi desenvolvido em 2003 e 2004 no Centro Agropecuário da Palma, na área experimental do Centro de Genômica e Fitomelhoramento, localizado no município de Capãodo-Leão (RS).

As linhagens de trigo com ausência e presença do caráter stay-green empregadas no estudo foram desenvolvidas de 1999 a 2001, utilizando-se duas épocas de semeadura por ano, verão e inverno e sob condições de telado e campo. Foram realizados cruzamentos entre as linhagens TB438 e TB188, a fim de obter a geração $F_{1}$ para os dois retrocruzamentos e autofecundação para formação da população $F_{2}$. Por meio de avanços de gerações foram obtidas linhagens distintas para o tipo de maturação (G: stay-green) e (Z: sincronizada). Além disso, foram direcionados os retrocruzamentos um e dois, respectivamente $\mathrm{RC}_{1} \mathrm{~F}_{1}$ $\left(\mathrm{P}_{1} / / \mathrm{P}_{1} / \mathrm{P}_{2}\right)$ e $\mathrm{RC}_{2} \mathrm{~F}_{1}\left(\mathrm{P}_{2} / / \mathrm{P}_{1} / \mathrm{P}_{2}\right)$, sendo a partir daí, autofecundadas até atingir a homozigose, e selecionadas plantas para a presença e ausência do caráter stay-green.

Desse modo, foram obtidas sete linhagens stay-green (G30, G39, G47, G53, G65, G71 e G74) e cinco de maturação sincronizada (Z31, Z37, Z49, Z57 e Z69) pelo avanço de gerações até $F_{n}$. Pelos retrocruzamentos, foram obtidas linhagem stay-green $\left(\mathrm{RC}_{1} \mathrm{G} 32\right)$ e sete sincronizadas $\left(\mathrm{RC}_{1} \mathrm{Z} 43, \mathrm{RC}_{1} \mathrm{Z} 45\right.$, $\mathrm{RC}_{1} \mathrm{Z55}, \mathrm{RC}_{1} \mathrm{Z58}, \mathrm{RC}_{1} \mathrm{Z68}, \mathrm{RC}_{1} \mathrm{Z72}$ e $\mathrm{RC}_{1} \mathrm{Z76}$ ) pelo retrocruzamento um, e seis linhagens stay-green ( $\mathrm{RC}_{2} \mathrm{G} 34, \mathrm{RC}_{2} \mathrm{G} 40, \mathrm{RC}_{2} \mathrm{G} 46, \mathrm{RC}_{2} \mathrm{G} 54, \mathrm{RC}_{2} \mathrm{G} 62 \mathrm{e}$ $\left.\mathrm{RC}_{2} \mathrm{G} 67\right)$ e quatro sincronizadas $\left(\mathrm{RC}_{2} \mathrm{Z} 35, \mathrm{RC}_{2} \mathrm{Z} 42\right.$, $\mathrm{RC}_{2} \mathrm{Z} 56$ e $\mathrm{RC}_{2} \mathrm{Z} 61$ ) pelo retrocruzamento dois.

As constituições genéticas de trigo TB438 (portador do caráter stay-green) e TB188 (maturação sincronizada) foram selecionadas pelo programa de 
melhoramento da Embrapa Clima Temperado (CPACT), em Pelotas (RS). Esses genótipos foram obtidos via recombinação em seleção recorrente com várias linhagens promissoras, cujo caráter stay-green e outros revelaram senescência sincronizada.

Foram incluídos no ensaio, também, os genótipos de trigo empregados como testemunha nos experimentos de produtividade de grãos (BRS179, BRS177, BR23, EMBRAPA40 e CEP27).

O delineamento experimental empregado foi o de blocos casualizados com três repetições. Foram avaliados 37 genótipos no total. A unidade experimental foi composta de cinco fileiras de $3 \mathrm{~m}$ de comprimento e espaçamento de $0,20 \mathrm{~m}$, utilizando-se densidade de semeadura de 300 sementes viáveis por metro quadrado. A adubação de base foi realizada de acordo com a análise do solo, e o controle de invasoras realizado através de capinas manuais e aplicações de herbicida de pós-emergência. Também, foram feitas aplicações de fungicidas para o controle de moléstias da parte aérea, conforme recomendações técnicas para a cultura do trigo (CSBPT, 2004). O caráter produtividade de grãos foi estimado pela extrapolação da produtividade de grãos obtida na unidade experimental para um hectare.

Os dados foram submetidos à análise de variância, comparação de médias de grupos (contrastes) e comparação de médias dentro e entre anos.

\section{RESULTADOS E DISCUSSÃO}

Os resultados inseridos na tabela 1 (Efeito Geral) evidenciam a existência de diferença significativa entre os genótipos avaliados, possibilitando prever a existência de variabilidade entre os 37 genótipos analisados. Além disso, entre os anos de cultivo também foram detectadas diferenças. Igualmente, a análise confirmou a presença de interação ano $x$ genótipo, estabelecendose a necessidade de avaliação dos genótipos em cada ano de cultivo, a fim de analisar com clareza a natureza de seus efeitos simples. Portanto, pelos resultados da tabela 1 (Efeito Fixo), é confirmada a existência de comportamento distinto entre os genótipos avaliados em cada ano de cultivo.

Devido aos genótipos estarem direcionados visando à presença e ausência do caráter stay-green e tendo como base, a formação destas linhagens por meio de retrocruzamentos e de sucessivas autofecundações a partir do $\mathrm{F}_{1}$, o conjunto de genótipos testados formaram uma estrutura de interesse, sugerindo análise eficaz e sucinta pela decomposição de polinômio ortogonais (contrastes) para cada ano de cultivo (Tabela 2).
No primeiro contraste formado, foi evidenciada a existência de diferenças entre os genótipos portadores do caráter stay-green com os de maturação sincronizada, visto que em 2003, a produtividade média de grãos obtida foi, respectivamente, de 2.625 $\mathrm{kg} \mathrm{ha}^{-1}$ contra $2.196 \mathrm{~kg} \mathrm{ha}^{-1}$. Esse resultado também foi evidenciado, em 2004, quando o desempenho dos genótipos do grupo stay-green foi superior, com valor médio de $2.301 \mathrm{~kg} \mathrm{ha}^{-1}$ contra $1.649 \mathrm{~kg} \mathrm{ha}^{-1}$ do grupo sincronizado. Considerando as linhagens provenientes apenas de autofecundação ( $\mathrm{G} \times \mathrm{Z})$, novamente os genótipos do grupo stay-green indicaram superioridade nos dois anos de avaliação, com $2.653 \mathrm{~kg} \mathrm{ha}^{-1}$ do grupo stay-green contra $2.282 \mathrm{~kg} \mathrm{ha}^{-1}$ do sincronizado em 2003. Em 2004, a diferença foi ainda mais expressiva, com produtividade média de grãos de $2.460 \mathrm{~kg} \mathrm{ha}^{-1}$ do stay-green contra $1.498 \mathrm{~kg} \mathrm{ha}^{-1}$ do sincronizado.

Tabela 1. Análise de variância (Geral e Fixo) para o caráter produtividade de grãos, considerando os 37 genótipos de trigo com ausência e presença do caráter "stay-green" avaliados em dois anos de cultivo. FAEM/UFPel 2006

\begin{tabular}{|c|c|c|c|}
\hline \multicolumn{2}{|c|}{ Fonte de variação (Geral) } & GL & $\mathrm{QM}_{\text {Produtividade }}$ \\
\hline \multicolumn{2}{|l|}{ Modelo } & 75 & $687947,53^{*}$ \\
\hline \multicolumn{2}{|l|}{ Genótipo } & 36 & $840821,35^{*}$ \\
\hline \multicolumn{2}{|l|}{ Ano } & 1 & $11714837,88^{*}$ \\
\hline \multicolumn{2}{|l|}{ Ano x Genótipo } & 36 & $265667,92 *$ \\
\hline \multicolumn{2}{|l|}{ Bloco } & 2 & $23806,47^{\mathrm{ns}}$ \\
\hline \multicolumn{2}{|l|}{ Erro } & 146 & 65403,07 \\
\hline \multicolumn{2}{|l|}{ Total } & 221 & - \\
\hline \multicolumn{2}{|l|}{ Média Geral } & - & 2221,824 \\
\hline \multicolumn{2}{|l|}{ CV $(\%)$} & - & 11,51 \\
\hline \multirow{2}{*}{\multicolumn{2}{|c|}{$\begin{array}{l}\text { Fonte de } \\
\text { Variação (Fixo) }\end{array}$}} & \multicolumn{2}{|c|}{$\mathrm{QM}_{\text {Produtividade }}$} \\
\hline & & 2003 & 2004 \\
\hline Genótipo & 36 & $378214,64^{*}$ & $728274,63^{*}$ \\
\hline Erro & 74 & 58507,14 & 71174,76 \\
\hline Total & 110 & - & - \\
\hline Média Geral & - & 2451,54 & 1992,11 \\
\hline CV $(\%)$ & - & 9,87 & 13,39 \\
\hline
\end{tabular}

$\mathrm{GL}=$ Graus de liberdade. $\mathrm{QM}=$ Quadrado médio. $\mathrm{CV}=$ Coeficiente de variação. * significativo a $5 \%$ de probabilidade. ${ }^{\text {ns }}$ não significativo.

Tais resultados atestam as potencialidades do caráter stay-green, objeto de estudo em diferentes espécies cultivadas, revelando correlações positivas com a produtividade de grãos e seus componentes (THOMAs e Smart, 1993; Cukadar-Olmedo e Miller, 1997; Silva et al., 2005). Esse caráter foi utilizado por MсвEE et al. (1983) em sorgo e no trigo por Silva (2005), como alternativa para promover um efetivo aumento funcional da área foliar, na duração da capacidade fotossintética das folhas e colmos, após a maturidade fisiológica, promovendo maior enchimento do produto final (grão). 
Tabela 2. Teste aplicado aos distintos grupos por contrastes estabelecidos e suas respectivas médias da produtividade de grãos em kg ha-1 ${ }^{-1}$ considerando 37 genótipos de trigo com tipo de maturação "stay-green" e sincronizado, avaliados em dois anos de cultivo. FAEM/UFPel, 2006

\begin{tabular}{|c|c|c|c|c|}
\hline \multirow{2}{*}{ Contraste } & \multicolumn{2}{|c|}{ Produtividade 2003} & \multicolumn{2}{|c|}{ Produtividade 2004} \\
\hline & QM & Médias & $\mathrm{QM}$ & Médias \\
\hline $\operatorname{SG}\left({ }^{1}\right) \times \operatorname{SZ}\left({ }^{2}\right)$ & $4426556^{*}$ & $2625,93 \times 2196,22$ & $10149118,00^{*}$ & $2301,31 \times 1649,75$ \\
\hline$G\left({ }^{3}\right) \times Z\left({ }^{4}\right)$ & $1203802^{*}$ & $2653,05 \times 2282,14$ & $8100841,98^{*}$ & $2460,19 \times 1498,00$ \\
\hline $\operatorname{RC} 1 G\left({ }^{5}\right) \times \operatorname{RC} 1 Z\left({ }^{6}\right)$ & $667548^{*}$ & $2618,67 \times 2114,38$ & $3570000,60 *$ & $2902,00 \times 1735,81$ \\
\hline $\operatorname{RC} 2 \mathrm{G}\left({ }^{7}\right) \times \operatorname{RC} 2 Z\left({ }^{8}\right)$ & $1762596^{*}$ & $2222,61 \times 2166,17$ & $607609,80^{*}$ & $2059,00 \times 1768,50$ \\
\hline $\mathrm{SG} \times \mathrm{T}\left({ }^{9}\right)$ & $334887^{*}$ & $2625,93 \times 2798,47$ & $59586,81^{*}$ & $2301,31 \times 2228,53$ \\
\hline$S Z \times T$ & $4212311^{*}$ & $2196,22 \times 2798,47$ & $3882906,11^{*}$ & $1649,75 \times 2228,53$ \\
\hline SG $\times$ BRS179 & $240462^{*}$ & $2625,93 \times 2918,33$ & $26450,69 \mathrm{~ns}$ & $2301,31 \times 2204,33$ \\
\hline SG x BRS177 & $305786^{*}$ & $2625,93 \times 2955,67$ & $125981,36^{*}$ & $2301,31 \times 2089,67$ \\
\hline SG $\times$ BR23 & $34819^{*}$ & $2625,93 \times 2514,67$ & $105875,50 *$ & $2301,31 \times 2495,33$ \\
\hline SG $\times$ EMBRAPA40 & $3836 \mathrm{~ns}$ & $2625,93 \times 2589,00$ & $1093872,36^{*}$ & $2301,31 \times 1677,67$ \\
\hline SG x CEP27 & $425007^{*}$ & $2625,93 \times 3014,67$ & $394149,61^{*}$ & $2301,31 \times 2675,67$ \\
\hline SZ x BRS179 & $1479860^{*}$ & $2196,22 \times 2918,33$ & $871442,98^{*}$ & $1649,75 \times 2204,33$ \\
\hline SZ x BRS177 & $1636702^{*}$ & $2196,22 \times 2955,67$ & $548337,80^{*}$ & $1649,75 \times 2089,67$ \\
\hline $\mathrm{SZ} \times \mathrm{BR} 23$ & $288393^{*}$ & $2196,22 \times 2514,67$ & $2025888,48^{*}$ & $1649,75 \times 2495,33$ \\
\hline SZ $\times$ EMBRAPA40 & $438435^{*}$ & $2196,22 \times 2589,00$ & $2208,91 n s$ & $1649,75 \times 1677,67$ \\
\hline SZ x CEP27 & $1900671^{*}$ & $2196,22 \times 3014,67$ & $2982126,02^{*}$ & $1649,75 \times 2675,67$ \\
\hline ТВ438 $\times$ ТВ188 & $70200^{*}$ & $2233,33 \times 2449,67$ & $758992,67^{*}$ & $2042,33 \times 1331,00$ \\
\hline
\end{tabular}

$\left({ }^{1}\right)$ grupo de linhagens "stay-green". $\left({ }^{2}\right)$ grupo de linhagens sincronizadas. $\left({ }^{3}\right)$ linhagens "stay-green" obtidas por sucessivas autofecundações. $\left({ }^{4}\right)$ linhagens sincronizadas obtidas por sucessivas autofecundações. $\left({ }^{5}\right)$ linhagens sincronizadas obtidas pelo retrocruzamento um. $\left({ }^{6}\right)$ linhagens "stay-green" obtidas pelo retrocruzamento um. $\left({ }^{7}\right)$ linhagens sincronizadas obtidas pelo retrocruzamento dois. $\left({ }^{8}\right)$ linhagens "stay-green" obtidas pelo retrocruzamento dois. $\left({ }^{9}\right)$ média dos genótipos testemunha (BRS179, BRS177, BR23, EMBRAPA40 e CEP27). * significativo a 5\% de probabilidade. ${ }^{\text {ns }}=$ não significativo.

Os grupos de genótipos testados $\mathrm{RC}_{1} \mathrm{~F}_{\mathrm{n}} \mathrm{e}$ $\mathrm{RC}_{2} \mathrm{~F}_{\mathrm{n}}$, foram provenientes de um ciclo de retrocruzamento e de sucessivas autofecundações no direcionamento de combinações alélicas distintas com base na presença e ausência do caráter stay-green. Desse modo, analisando-se as constituições genéticas de $R_{1} G$ em comparação ao $R C_{1} Z$, também foram observadas diferenças entre os grupos, com a menor produtividade de grãos apresentada pelas linhagens do grupo sincronizado, o mesmo também observado pelos genótipos dos distintos grupos de maturação no $\mathrm{RC}_{2}$. Ademais, foi possível detectar desempenhos distintos observados quanto à produtividade de grãos nos genótipos $R C_{1} G$ e $R C_{2} G$ em comparação as linhagens dos grupos $\mathrm{RC}_{1} \mathrm{Z}$ e $\mathrm{RC}_{2} \mathrm{Z}$, determinando que na medida em que os genótipos foram retrocruzados com o genitor TB438 (portador do gene stay-green) e direcionados à homozigose, favoreceu uma produtividade de grãos superior. Portanto, a presença de alelos favoráveis nestas constituições genéticas foi confirmada pelo desempenho obtido nos dois anos de avaliação, principalmente em 2004, onde o $R_{1} G$ e $R C_{1} Z$ evidenciaram valores de produtividade de grãos de 2.902 e $1.735 \mathrm{~kg} \mathrm{ha}^{-1}$, respectivamente, e $\mathrm{RC}_{2} \mathrm{G}$ com $\mathrm{RC}_{2} \mathrm{Z}$, neste mesmo ano, com médias de 2.059 e $1.768 \mathrm{~kg} \mathrm{ha}^{-1}$, respectivamente. Esse fato, de certa forma, caracteriza a possibilidade do emprego do método de retrocruzamento como uma técnica eficiente, pois além de permitir a transferência do caráter stay-green, proporcionou aumento na freqüência de combinações alélicas distintas para obtenção de genótipos superiores.

Segundo Lorencetti et al. (2006), o retrocruzamento é um método utilizado frequentemente com o objetivo de transferir porções genômicas de genótipos não adaptados ou espécies selvagens para genótipos-elite deficiente neste aspecto. Essas porções genômicas, normalmente, são caracteres de controle qualitativo como resistência a pragas e moléstias. No entanto, em relação ao controle genético do caráter produção de grãos e seus componentes primários, as informações disponíveis sugerem a existência de vários genes controlando tais caracteres. Desta forma, o direcionamento de hibridações que permite o aumento de alelos desejáveis em um individuo pode ser viabilizado pelo emprego do retrocruzamento aliado ao caráter stay-green, que está fortemente associado à produtividade de grãos. 
Considerando-se a média de todos os genótipos stay-green (SG) e do grupo sincronizado (SZ), em comparação à média geral de todos os genótipos-padrão (T): BRS179, BRS177, BR23, EMBRAPA40 e CEP27 em 2003, foram observadas diferenças na produtividade de grãos, com superioridade da média dos padrões sobre a média das linhagens com e sem a presença do caráter staygreen. No entanto, esta diferença estabelecida entre SG x T foi de $173 \mathrm{~kg}$, enquanto no SZ x T, de $602 \mathrm{~kg}$ de produtividade de grãos.

Em 2004, essa diferença no SG x T não foi observada, ao contrário das linhagens de maturação sincronizada, em que se constataram produtividade inferior de 578 kg em relação à média padrão.

Levando-se em consideração o contraste do grupo stay-green com cada genótipo padrão empregado no estudo, é possível perceber que em 2003, os genótipos BRS177, BRS179 e CEP27 tiveram desempenho superior. Porém, em 2004, tais diferenças não foram confirmadas, indicando, possivelmente, maior instabilidade desses genótipos-padrão, frente aos anos de avaliação, visto que, em anos ruins, é de se esperar melhor desempenho na produtividade de grãos em genótipos mais adaptados ao local de cultivo. Além disso, neste mesmo ano de avaliação, foi evidenciada a superioridade das linhagens do grupo SG em relação ao genótipo EMBRAPA40, com diferenças na produtividade de grão em torno de 624 kg. Em comparação aos genótipos BR23 e CEP27, as linhagens SG foram estatisticamente inferiores, com uma diferença na produtividade de grão de 194 e 374 $\mathrm{kg}$ respectivamente.

Todas as linhagens do tipo de maturação sincronizada foram inferiores em comparação a cada genótipo padrão nos dois anos de avaliação, exceto para a cultivar EMBRAPA40 no ano de 2004. Entretanto, tais resultados confirmam a superioridade das linhagens portadoras do caráter stay-green sobre as de maturação sincronizada. Por outro lado, é visível que a garantia do sucesso na obtenção de genótipos promissores não está apenas sob controle de um único caráter, determinando, sobretudo, a necessidade de ajuste da constituição genética desenvolvida pela máxima presença de alelos favoráveis que, aliado à expressão do caráter staygreen, poderá contribuir fortemente para alteração do platô da produtividade de grãos em trigo. SiLva et al. (2005) destacam que para incrementar a produtividade de grãos, parece ser necessário que os programas de melhoramento genético devem se orientar no aproveitamento da importância relativa dos componentes de rendimento em trigo.
Pelos dados da tabela 3, é possível analisar de modo geral, o desempenho individual de cada linhagem com e sem a presença do caráter stay-green, incluindo os padrões nos dois anos de avaliação para o caráter produtividade de grãos. Desta forma, em 2003, os maiores destaques foram as linhagens G71, G39, G47, G53, $\mathrm{RC}_{2} \mathrm{G} 62$ e $\mathrm{RC}_{2} \mathrm{G} 46$, do grupo stay-green com desempenhos superiores neste ano de cultivo, e de comportamento similar aos cultivares-padrão CEP27, BRS177 e BRS179. Ademais, grande parte das linhagens do grupo stay-green foram de classe " $b$ " pelo segundo melhor desempenho, ao contrário do grupo sincronizado - Z49, $\mathrm{RC}_{1} \mathrm{Z} 55, \mathrm{RC}_{1} \mathrm{Z72}$ e $\mathrm{RC}_{2} \mathrm{Z} 56$ - que revelaram os menores valores médios. Esses resultados podem ser confirmados com base naqueles observados por Silva (2002), evidenciando que o período de enchimento de grãos, nos genótipos de trigo stay-green avaliados, estava associado ao maior acúmulo de matéria seca, ao mesmo tempo em que a ausência desse caráter (genótipos de maturação sincronizada) determinava menor massa média de grãos.

Em 2004, os melhores desempenhos foram obtidos nos genótipos G71, G39, G53, G65, RC 1 G32, $\mathrm{RC}_{1} \mathrm{Z68}$ e $\mathrm{RC}_{2} \mathrm{G} 40$, junto aos padrões CEP27 e BR23, determinando, novamente, os melhores desempenhos para os genótipos do tipo de maturação stay-green. Grande parte dos demais genótipos, com ausência do caráter, revelou classe " $c$ " de menor desempenho.

Mediante avaliação dos distintos genótipos, com base no desempenho dos dois anos de avaliação, é possível perceber o grande destaque conferido a G71, G39 e G53 que, no decorrer desses dois anos de cultivo, tiveram o mesmo comportamento, indicando de certa forma estabilidade fenotípica com base em anos, aliado à elevada produtividade de grãos. Essa dificuldade foi relatada por Allard (1999), constatando que os anos de cultivo representam o efeito de ambiente que proporciona ao melhorista a maior dificuldade na seleção. Observação também relevante foi a forte redução no potencial produtivo de 2003 para 2004 de $2.449 \mathrm{~kg} \mathrm{ha}^{-1}$ para $1.331 \mathrm{~kg} \mathrm{ha}^{-}$ ${ }^{1}$ do genótipo TB188, ao contrário da TB438 que expressou comportamento mais similar nos dois anos de experimento, atestando que genótipos com presença do caráter stay-green poderão ter maior estabilidade. Essas evidências foram relatadas por Duvick (1992) e Russel (1986), observando que genótipos de milho que manifestaram o caráter verde na maturação fisiológica, revelaram maior produtividade de grãos, redução no acamamento e maior resistência à morte prematura das plantas. Assim, de acordo com Duncan et al. (1981), mantendo a planta verde após o florescimento até o enchimento total dos grãos, seria alternativa eficaz para garantir maior translocação de fotoassimilados até os grãos, principalmente, em condições de ambientes adversos. 
Tabela 3. Análise de médias da produtividade de grãos em $\mathrm{kg} \mathrm{ha}^{-1}$, comparando 37 genótipos de trigo com tipo de maturação "stay-green" e sincronizado incluindo padrões, em dois anos de avaliação. FAEM/UFPel, 2006

\begin{tabular}{|c|c|c|}
\hline Genótipo & $\begin{array}{l}\text { Produtividade } \\
(2003)\end{array}$ & $\begin{array}{c}\text { Produtividade } \\
(2004) \\
\end{array}$ \\
\hline G71 $\left({ }^{1}\right)$ & 3055,7 a A & 2663,3 a $A$ \\
\hline G39 & 2734,7 a $\mathrm{A}$ & 2760,3 a $\mathrm{A}$ \\
\hline G47 & 2740,7 a A & 2210,7 b B \\
\hline G53 & 2907,3 a A & 2443,0 a A \\
\hline G30 & 2414,7 b A & 2241,7 b A \\
\hline G74 & 2407,3 b A & 2379,0 b A \\
\hline G65 & 2311,0 c A & 2523,3 a A \\
\hline $\mathrm{Z37}\left({ }^{2}\right)$ & $2626,0 \mathrm{~b} \mathrm{~A}$ & 1578,3 с B \\
\hline Z69 & 2455,7 b A & 1415,7 с В \\
\hline Z31 & 2359,7 с A & 1601,7 с В \\
\hline Z57 & 2087,7 с A & 1488,3 с A \\
\hline Z49 & $1881,7 \mathrm{~d} \mathrm{~A}$ & 1406,0 с A \\
\hline $\mathrm{RC} 1 \mathrm{G} 32\left({ }^{3}\right)$ & 2618,7 b A & 2902,0 a A \\
\hline $\mathrm{RC} 1 \mathrm{Z68}\left({ }^{4}\right)$ & 2478,7 b A & 2524,0 a A \\
\hline RC1Z43 & 2307,3 с A & 2376,3 b A \\
\hline RC1Z76 & 2259,0 с A & 1705,3 с B \\
\hline RC1Z55 & $1741,0 \mathrm{~d} \mathrm{~A}$ & 1634,0 с A \\
\hline RC1Z58 & 2077,7 с A & 1480,3 с A \\
\hline RC1Z72 & $1755,7 \mathrm{~d} A$ & 937,3 с B \\
\hline RC1Z45 & 2181,3 с A & 1493,3 с В \\
\hline RC2G62 $\left({ }^{5}\right)$ & 2941,0 a A & 2249,0 b B \\
\hline RC2G46 & 2922,3 a A & 1756,7 с В \\
\hline RC2G34 & 2611,0 b A & 1562,7 с B \\
\hline RC2G67 & 2533,3 b A & 1923,3 с В \\
\hline RC2G40 & $2524,0 \mathrm{~b}$ A & 2787,7 a $A$ \\
\hline RC2G54 & 2434,0 b A & 2074,7 b B \\
\hline RC2Z35 (6) & 2531,0 b A & 1555,0 с В \\
\hline RC2Z56 & $1796,7 \mathrm{~d}$ A & 1644,0 с A \\
\hline RC2Z61 & 2026,0 с A & 2051,3 b A \\
\hline RC2Z42 & 2311,0 c A & 1823,7 с A \\
\hline BRS179 & 2918,3 a A & 2204,3 b B \\
\hline BRS177 & 2955,7 a A & 2089,7 b B \\
\hline BR23 & 2514,7 b A & 2495,3 a A \\
\hline EMBRAPA40 & 2589,0 b A & 1677,7 с B \\
\hline CEP27 & 3014,7 a A & 2675,7 a $A$ \\
\hline TB188 & 2449,7 b A & 1331,0 с B \\
\hline TB438 & 2233,3 с A & 2042,3 b B \\
\hline
\end{tabular}

$\left.{ }^{1}\right)$ linhagens "stay-green" obtidas por sucessivas autofecundações. $\left({ }^{2}\right)$ linhagens de maturação sincronizada obtida por sucessivas autofecundações. ( $\left({ }^{3}\right)$ linhagens "stay-green" obtidas pelo retrocruzamento um. $\left({ }^{4}\right)$ linhagens sincronizadas obtidas pelo retrocruzamento um. $\left({ }^{5}\right)$ linhagens "stay-green" obtidas pelo retrocruzamento dois. $\left({ }^{6}\right)$ linhagens sincronizadas obtidas pelo retrocruzamento dois. Médias seguidas pela mesma letra maiúscula na linha e médias seguidas pela mesma letra minúscula na coluna não diferem entre si a $5 \%$ de probabilidade pelo teste de Scott \& Knott.
Contudo, é possível verificar que a presença do alelo stay-green poderá contribuir fortemente para o incremento na produtividade de grãos para a formação de linhagens promissoras. Além disso, por se tratar de caráter cuja manifestação é controlada por poucos genes de grande efeito no caráter (SILVA, 1999), pode ser facilmente transferido por retrocruzamentos e submetido á forte pressão de seleção para potencializar a obtenção de linhagens de elevada produtividade de grãos.

\section{CONCLUSÕES}

1. O caráter stay-green auxilia no aumento da produtividade de grãos em trigo.

2. A presença de constituições genéticas superiores facilita os benefícios expressos pelo caráter stay-green na produtividade de grãos.

3. O caráter stay-green proporciona produtividade estável de grãos sob efeito de diferentes ambientes.

\section{AGRADECIMENTOS}

Os autores agradecem à CAPES e ao $\mathrm{CNPq}$ pela concessão de bolsas de Pós-Graduação, Iniciação Científica e suporte nesta pesquisa.

\section{REFERÊNCIAS}

ALLARD, R.W. Principles of plant breeding. New York: John Wiley \& Sons, 1999, 485p.

COMISSÃO SUL BRASILEIRA DE PESQUISA DE TRIGO. Recomendações da Comissão Sul-Brasileira de Pesquisa de Trigo. Passo Fundo: EMBRAPA-CNPT, 2004. 74p.

CUKADAR-OLMEDO, B.; MILLER, J.F. Inheritance of the staygreen trait in sunflower. Crop Science, Madison, v.37, n.1, p.150-153, 1997.

DUNCAN, R.R.; BOCKHOLT, A.J.; MILLER, F.R. Descriptive comparison of senescent and non-senescent sorghum genotypes. Agronomy Journal, Madison, v.73, n.5, p.849853, 1981.

DUVICK, D.N. Genetic contributions to advances in yield of U.S. maize. Maydica, Bergamo, v.37, n.1, p.69-79, 1992.

GENTINETTA, E.; CEPPI, D.; LEPORI, C.; PERICO, G.; MOTTO, M.; SALAMINI, F. A major gene for delayed senescence in maize - Pattern of photosynthates accumulation and inheritance. Plant Breeding, Berlin, v.97, n.3, p.193-203, 1986. 
GONG, Y.H.; ZHANG, J.; GAO, J.F.; LU, J.Y.; WANG, J.R. Slow export of photoassimilate from stay-green leaves during late grain-filling stage in hybrid winter wheat (Triticum aestivum L.). Journal of Agronomy and Crop Science, Oxford, v.191, n.4, p.292-299, 2005.

LORENCETTI, C.; CARVALHO, F.I.F.; OLIVEIRA, A.C.; VALÉRIO, I.P.;HARTWIG, I.; MARCHIORO, V.S.; VIEIRA, E.A. Retrocruzamento como uma estratégia de identificar genótipos e desenvolver populações segregantes promissoras em aveia. Ciência Rural, Santa Maria, v.36, n.4, p.1118-1125, 2006.

MCBEE, G.G; WASKOM, R.M.; MILLER, F.R.; CREELMAN, R.A. Effect of senescence and nonsenescence on carbohydrates in sorghum during late kernel maturity states. Crop Science, Madison, v.23, n.2, p.372-376, 1983.

OOSTEROM, E.J. van; JAYACHANDRAN, R.; BIDINGER, F.R. Diallel analysis of the stay-green trait and its components in sorghum. Crop Science, Madison, v.36, n.3, p.549-555, 1996.

RUSSEL, W.A. Contribution of breeding to maize improvement in the United States, 1920s-1980s. Iowa State Journal of Research, Ames, v.61, n.1, p.5-34, 1986.

SILVA, J.A.G. Caráter "stay-green e técnica de duplo-haplóides como estratégia no desenvolvimento de genótipos superiores em trigo. 2005. 90p. Tese (Doutorado) - Universidade Federal de Pelotas, Pelotas.

SILVA, S.A. Estimativa da herança do caráter "stay-green" em genótipos de trigo hexaplóide. 1999. 56p. Dissertação (Mestrado) - Universidade Federal de Pelotas, Pelotas.
SILVA, S.A. Caráter "stay-green" como uma estratégia de rendimento e qualidade de semente de trigo. 2002. 110p. Tese (Doutorado) - Universidade Federal de Pelotas, Pelotas.

SILVA, S.A.; CARVALHO, F.I.F.; NEDEL, J.L.; CRUZ, P.J.; PESKE, S.T.; SIMIONI, D.; CARGNIN, A. Enchimento de sementes em linhas quase isogênicas de trigo com presença e ausência do caráter "stay-green". Pesquisa Agropecuária Brasileira, Brasília, v.38, n.5, p.613-618, 2003.

SILVA, S.A.; CARVALHO, F.I.F.; NEDEL, J.L.; VASCONSELLOS, N.J.S.; CRUZ, P.J.;SIMIONI, D.;SILVA, J.A.G. Composição de subunidades de gluteninas de alto massa molecular (HMW) em trigos portadores do caráter "staygreen”. Ciência Rural, Santa Maria, v.34, n.3, p. 679-683, 2004.

SILVA, S.A.; CARVALHO, F.I.F.; NEDEL, J.L.; CRUZ, P.J.; SILVA, J.A.G.; CAETANO, V.R.; HARTWIG, I.; SOUZA, C.S. Análise de trilha para os componentes de rendimento de grãos em trigo. Bragantia, Campinas, v.64, n.2, p.191-196, 2005.

THOMAS, H.; SMART, C.M. Crop that stay green. Annals of Apllied Biology, Warwick, v.123, n.1, p.193-219, 1993.

WALULU, R.S.; ROSENOW, D.T.; WESTER, D.B.; NGUYEN, H.T. Inheritance of the stay green trait in sorghum. Crop Science, Madison, v.34, n.4, p.970-972, 1994. 